\title{
Sequential Inclusion of Two Berberine Cations in Cucurbit[8]uril Cavity: Kinetic and Thermodynamic Studies
}

\author{
Zsombor Miskolczy, László Biczók* \\ Institute of Materials and Environmental Chemistry, Research Centre for Natural \\ Sciences, Hungarian Academy of Sciences, P.O. Box 286, 1519 Budapest, Hungary
}

\footnotetext{
${ }^{*}$ Corresponding author. E-mail: biczok.laszlo@ttk.mta.hu
} 


\begin{abstract}
A combination of absorption and fluorescence spectroscopic studies with isothermal calorimetric titrations and stopped-flow measurements is a powerful way to reveal the thermodynamics and kinetics of inclusion complex formation with cucurbit[8]uril (CB8). The unique photophysical characteristics of berberine $\left(\mathrm{B}^{+}\right)$, a pharmaceutically important natural alkaloid, was exploited to distinguish the consecutive encapsulation processes, and to examine the confinement in CB8 cavity. The highly environment sensitive fluorescence lifetime of $\mathrm{B}^{+}$permitted of the selective detection of various cucurbituril complexes, and indicated to what extent the embedded guest is available for interaction with water. Highly stable 1:1 and 2:1 $\mathrm{B}^{+}$: CB8 complexes were produced due to the release of the high energy water molecules from the CB8 interior, and the second binding step proved to be almost 3 times more exothermic. The favorable entropy change appreciably contributed to the driving force of 1:1 encapsulation. Contrarily, the embedment of the second $\mathrm{B}^{+}$in $\mathrm{CB} 8$ led to substantial entropy diminution. The kinetics of encapsulation was followed in real time by recording the fluorescence intensity change after rapid mixing of $\mathrm{B}^{+}$and CB8. No evidence was found for intermediates. The rate constants of $(64 \pm 9) \times 10^{6}$, and $(5.0 \pm$ $0.5) \times 10^{6} \mathrm{M}^{-1} \mathrm{~s}^{-1}$ were found for $1: 1$ and $2: 1$ associations, whereas $3.8 \pm 0.6$, and $0.6 \pm 0.1 \mathrm{~s}^{-1}$ were obtained for the rate constants of the reverse processes at $283 \mathrm{~K}$, respectively.
\end{abstract}




\section{INTRODUCTION}

The utilization of cucurbiturils ( $\mathrm{CBn})$, a class of cavitands made of glycoluril units linked by methylene bridges, is a rapidly developing area of supramolecular chemistry. ${ }^{1-6}$ The remarkable binding capability of these rigid symmetrical macrocycles have great potential in catalysis, ${ }^{7-9}$ protection of compounds against decomposition, ${ }^{10,11}$ tuning of the properties of the encapsulated guests $^{6,12}$ as well as in the design of fluorescence assays ${ }^{13,14}$ and functional materials. ${ }^{2,5}$

The spacious cavity of the eight-membered homologue, CB8, can simultaneously accommodate two aromatic guests, ${ }^{15,16}$ and charge-transfer (CT) complex formation was observed inside the nonpolar cavity. ${ }^{17}$ Biedermann and Scherman demonstrated that the CT excited state is much more efficiently stabilized by the uniform negative electrostatic potential of the CB8 interior than in any polar solvents. ${ }^{18}$ They provided evidence for the CB8-promoted CT interaction between guests, and concluded that CT is not the dominant factor in the stabilization of the ternary complexes. The coinclusion of electron-deficient and electron-rich moieties facilitated the creation of host-stabilized supramolecular polymers, ${ }^{19,20}$ polyrotaxanes, ${ }^{21}$ molecular necklaces, ${ }^{22}$ vesicles, ${ }^{23}$ and rotaxane dendrimers. ${ }^{24}$ CB8 complexes of fluorescent guests were used to design photoswichable host-guest associates, ${ }^{25}$ and to detect catechol or dopamine. ${ }^{26}$ The reversibility of complex formation inside the host was exploited to construct molecular machines, and switches responding to redox reactions. ${ }^{24,27,28}$ Preferential binding of CB8-methyl viologen 1:1 complex was observed to N-terminal tryptophan in peptides. $^{29}$ Selective recognition and the stepwise encapsulation of two N-terminal tryptophan or phenylalanine residues were found for peptides in the presence of CB8. ${ }^{30}$ This cavitand greatly improved the binding affinity of 5,10,15,20-tetrakis(1-methyl-4-pyridinio)porphyrin, a promising 
photodynamic therapy sensitizer, towards bovine serum albumin due to ternary complex formation with the tryptophan residue of the protein. ${ }^{31}$

Despite the crucial importance of the knowledge of the entry and exit rates in many applications, very few information is available on the dynamics of the consecutive inclusion of two guests in CB8, and a complete kinetic analysis of the reversible binding steps have not been performed. On the basis of oscillatory rheological measurements, Scherman obtained $9.6 \times 10^{7}$ $\mathrm{M}^{-1} \mathrm{~s}^{-1}$ and $1200 \mathrm{~s}^{-1}$ for the association and dissociation rate constants of CB8 ternary complex formation of the polymer-linked methyl viologen and naphthoxy moieties. ${ }^{32}$ Sivaguru and coworkers examined the CB8-catalyzed photodimerization of 6-methylcoumarin, and found 1.1 $\mathrm{s}^{-1}$ and $0.18 \mathrm{~min}^{-1}$ for the pseudo-first order formation of 1:1 and 1:2 host:guest complexes. ${ }^{33}$ The ingression and egression rates were examined predominantly with cucurbit[6]uril (CB6), ${ }^{34-39}$ and only a few studies focused on the dynamics of cucurbit[7]uril (CB7) complexes. ${ }^{40-44}$ Kinetic studies provide mechanistic information that cannot be obtained from thermodynamic results. ${ }^{45-46}$

$\mathrm{CBn}$ hosts have considerable potential in the delivery, stabilization, solubilization and controlled release of drugs. ${ }^{47-48}$ We have demonstrated that berberine $\left(\mathrm{B}^{+}\right)$, a pharmaceutically important isoquinoline alkaloid, is an excellent guest for the investigation of the complex formation dynamics with CB7. ${ }^{44}$ Activation enthalpy of 32 and $69 \mathrm{~kJ} \mathrm{~mol}^{-1}$ were found for the association and dissociation implying that the tight carbonyl-laced portal of the host constituted a steric barrier.

Herein, we report the first combined kinetic and thermodynamic study of the reversible 1:1 and 2:1 inclusion in CB8 cavity. Our main objective was to reveal how the enlargement of the macrocycle to CB8 affects the fluorescence behavior, stoichiometry of binding, and the thermodynamics of the inclusion complex formation with $\mathrm{B}^{+}$. Special attention was devoted to 
the detailed investigation of the host-guest interaction kinetics to obtain information on the elementary reaction steps, and to clarify whether any intermediate is involved in the reaction mechanism. We demonstrate that the homoternary complex formation is highly exothermic and rapid despite the Coulomb repulsion between the two cationic guests. The formulas of the investigated compounds are displayed in Scheme 1.

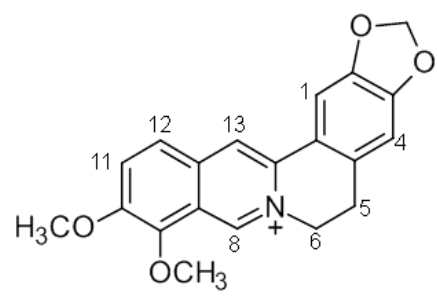

Berberine $\left(\mathrm{B}^{+}\right)$

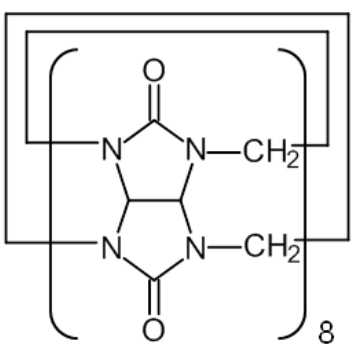

Cucurbit[8]uril (CB8)

Scheme 1 Chemical structure of the studied compounds

\section{EXPERIMENTAL}

Berberine chloride (Sigma) was chromatographed on silica gel (Merck) column eluting with ethanol. High-purity CB7 and CB8 were kindly provided by Dr. Anthony I. Day (University of New South Wales, Canberra, Australia). Experiments were carried out in neat water that was freshly distilled three times from dilute $\mathrm{KMnO}_{4}$ solution. The UV-visible absorption spectra were recorded on an Agilent Technologies Cary60 spectrophotometer. Corrected fluorescence spectra were obtained on a Jobin-Yvon Fluoromax-P photoncounting spectrofluorometer. Stopped-flow measurements were performed with the same instrument using an Applied Photophysics RX2000 rapid mixing accessory and a pneumatic drive. The temperature of the samples was controlled with a Julabo F25-ED thermostat. As initial conditions of the stoppedflow experiments, we give the concentration of the reactants immediately after mixing. Further 
experimental details have been reported in a former paper. ${ }^{44}$ Fluorescence decays were measured with time-correlated single-photon counting technique using the previously described instrument. ${ }^{49}$ The results of spectrophotometric and fluorescence titrations were analyzed with homemade programs written in MATLAB 7.9. Semiempirical calculations with AM1 method were carried out with HyperChem 8.0 program.

Isothermal titration calorimetry was carried out with a VP-ITC (MicroCal) instrument at $298 \mathrm{~K}$. All solutions were degassed prior to titration. $\mathrm{B}^{+}$solution $(390 \mu \mathrm{M})$ was added stepwise in a series of 46 injections ( $6 \mu \mathrm{l}$ each) from the computer-controlled microsyringe at an interval of $270 \mathrm{~s}$ into a $1.433 \mathrm{ml}$ cell containing $21 \mu \mathrm{M} \mathrm{CB} 8$ solution, while stirring at $300 \mathrm{rpm}$. The dilution heat, which was determined by adding $\mathrm{B}^{+}$solution into water under the same condition as in the titration of CB8 was subtracted. The results were analyzed with the two consecutive binding model using Microcal ORIGIN software. The first data point was always removed. The titrations were repeated three times.

\section{RESULTS}

\section{Absorption and fluorescence characteristics of CB8 complexes}

The absorption spectrum of $3.5 \mu \mathrm{M} \mathrm{B}^{+}$shows distinct changes below and above $2.2 \mu \mathrm{M}$ CB8 concentration indicating the formation of two types of complexes. At low CB8 concentration, the hypochromicity of the bands and the slight red-shift of the lowest energy absorption maximum (red line in Figure 1A) are attributed to the inclusion of two $\mathrm{B}^{+}$in the nonpolar cavity of the host. Further addition of CB8 brings about small hyperchromicity accompanied by a blueshift for the first two absorption bands implying the transformation from 2:1 (2B $\left.{ }^{+} @ \mathrm{CB} 8\right)$ to 1:1 ( $\left.\mathrm{B}^{+} @ \mathrm{CB} 8\right)$ complexes. The blue line in Figure 1A displays the absorption of the latter species. 

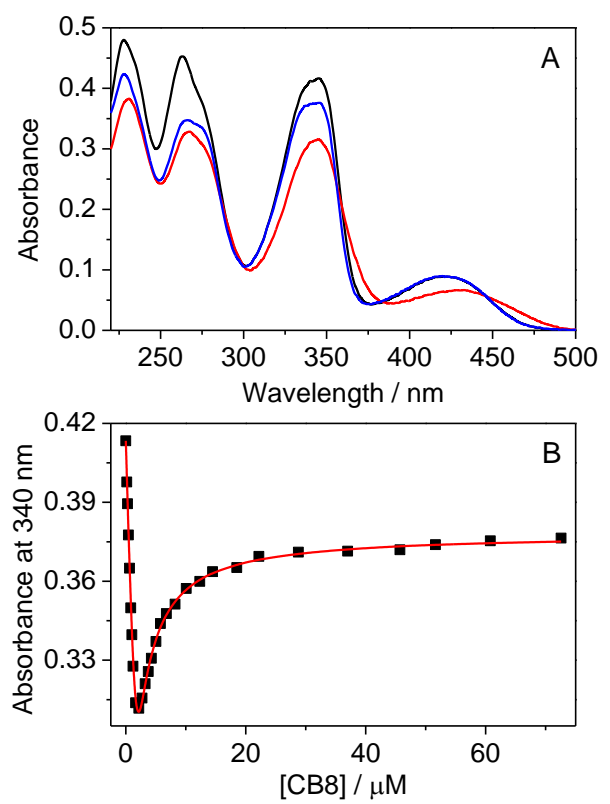

Figure 1. (A) Alteration of the absorption spectrum of $3.5 \mu \mathrm{M} \mathrm{B}{ }^{+}$upon addition of 0 (black line), 2.2 (red line), and $61 \mu \mathrm{M}$ (blue line) $\mathrm{CB} 8$ at $298 \mathrm{~K}$. The optical path is $5 \mathrm{~cm}$. (B) Absorbance change as a function of CB8 concentration at $340 \mathrm{~nm}$. The line represents the fitted function.

The lowest energy absorption bands for $\mathrm{B}^{+}$and $\mathrm{B}^{+} @ \mathrm{CB} 8$ barely differ. The absorbance variation at $340 \mathrm{~nm}$ with $\mathrm{CB} 8$ concentration reaches a minimum at less than $1: 1 \mathrm{~B}^{+}: \mathrm{CB} 8$ stoichiometric ratio (Figure 1B) suggesting that not only a single $\mathrm{B}^{+}$is confined in $\mathrm{CB}$. The absorbance values were analyzed by a homemade MATLAB 7.9 program as described in our previous paper. ${ }^{49}$ Assuming consecutive inclusion of $2 \mathrm{~B}^{+}$, the nonlinear least-squares fit of the experimental data provided $\mathrm{K}_{1}=\left[\mathrm{B}^{+} @ \mathrm{CB} 8\right] /\left(\left[\mathrm{B}^{+}\right][\mathrm{CB} 8]\right)=(9.5 \pm 1.4) \times 10^{6} \mathrm{M}^{-1}$ and $\mathrm{K}_{2}=\left[2 \mathrm{~B}^{+} @ \mathrm{CB} 8\right] /\left(\left[\mathrm{B}^{+}\right]\left[\mathrm{B}^{+} @ \mathrm{CB} 8\right]\right)$ $=(2.5 \pm 0.6) \times 10^{6} \mathrm{M}^{-1}$ for the equilibrium constants at $298 \mathrm{~K}$. Unfortunately, the low solubility of the complexes thwarted the determination of their structure by NMR spectroscopy. Quantum chemical calculations with AM1 semiempirical method using HyperChem 8.0 program provided 

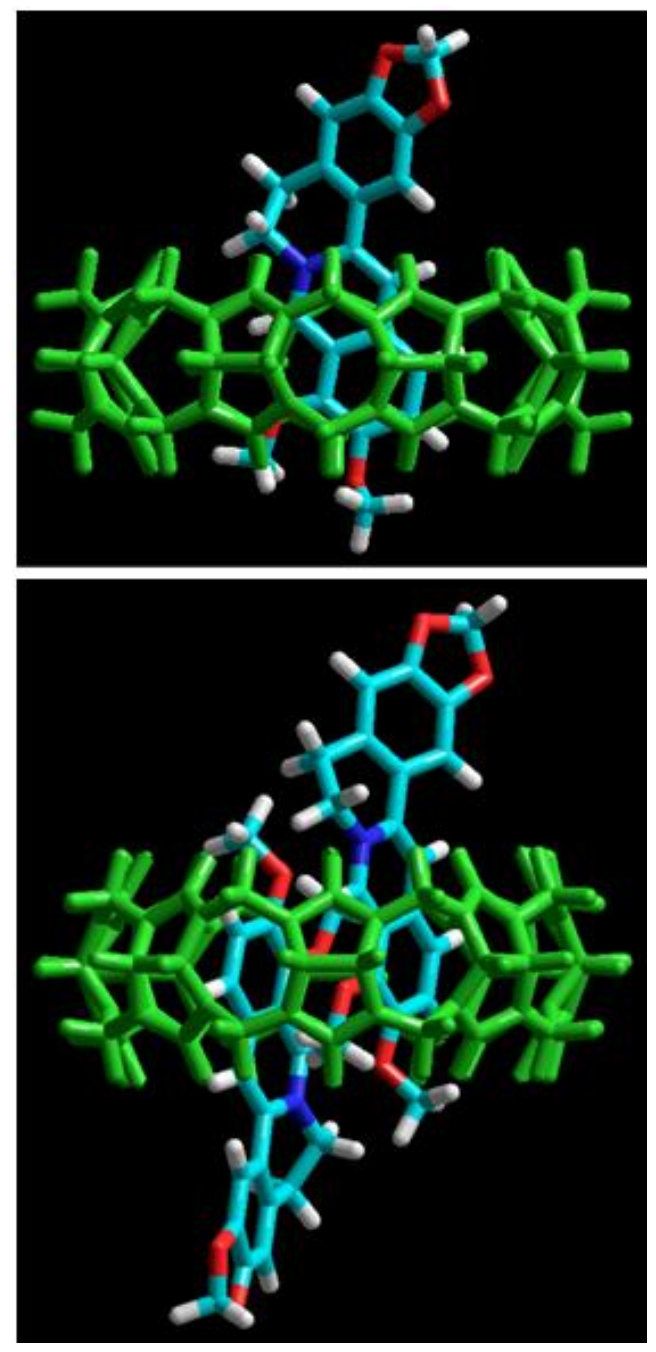

Figure 2. Energy-minimized structures for $1: 1$ and $2: 1$ complexes calculated by AM1 semiempirical method. Color codes: CB8, green; $\mathrm{B}^{+}$, oxygen, red; nitrogen, blue; carbon, light blue, hydrogen, white.

the energy-minimized structures. (Figure 2) The spatial arrangement of $\mathrm{B}^{+}$in $\mathrm{CB} 8$ closely resembles that of $\mathrm{B}^{+} @ \mathrm{CB} 7 .^{50}$ The dimethoxy isoquinoline moiety, whose positive charge is delocalized, is included in the hydrophobic core of the host, and the heterocyclic nitrogen is located close to the carbonyl-laced portal. The benzodioxole end of the molecule is not embedded because the height ${ }^{51}$ of CB8 is only $0.91 \mathrm{~nm}$. The $0.69 \mathrm{~nm}$ portal diameter and the 
$0.88 \mathrm{~nm}$ equatorial internal width of the host ${ }^{51}$ permit partial encapsulation of two $\mathrm{B}^{+}$cations. The benzodioxole groups of the 2:1 complex are oriented to opposite directions, whereas the isoquinoline rings are slightly less deeply immersed in CB8 than in the case of the 1:1 associate. CB8 has a rather uniform negative electrostatic potential inside the cavity and at the portal area, ${ }^{18}$ which probably contributes to the screening of the electrostatic repulsion between the two positively charged guests.

$\mathrm{B}^{+}$emits very weak fluorescence in water, for which quantum yield of $4.7 \times 10^{-4}$ was reported in $\mathrm{D}_{2} \mathrm{O} .{ }^{52}$ Gradual addition of $\mathrm{CB} 8$ to $3.6 \mu \mathrm{M} \mathrm{B}^{+}$solution leads to a substantial initial growth of the fluorescence intensity reaching a maximum in the presence of $2.0 \mu \mathrm{M}$ CB8. (Figure 3) In the second stage of the titration, a hypsochromic displacement and intensity
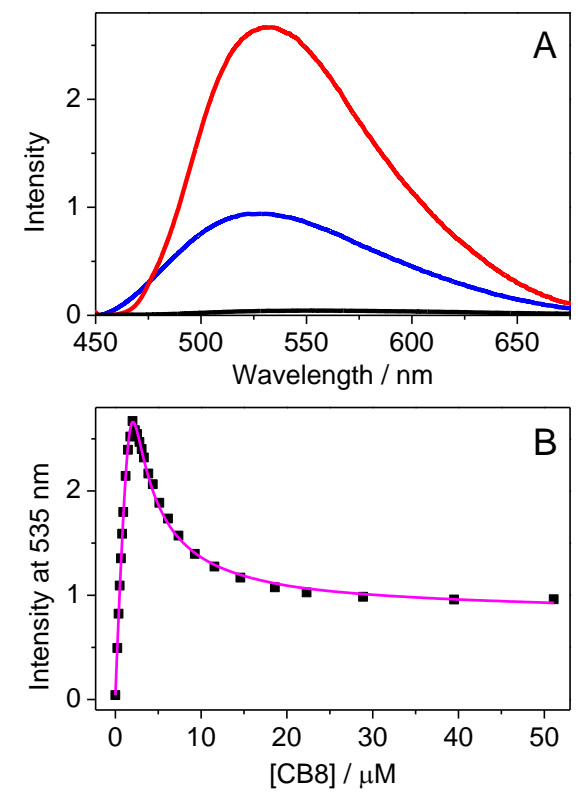

Figure 3. (A) Fluorescence spectra of $3.6 \mu \mathrm{M} \mathrm{B}^{+}$in the presence of 0 (black line), 2.0 (red line), and $114 \mu \mathrm{M}$ CB8 (blue line) at $298 \mathrm{~K}$. (B) Fluorescence intensity at $535 \mathrm{~nm}$ as a function of CB8 concentration. The line displays the result of nonlinear least-squares analysis. Excitation took place at $372 \mathrm{~nm}$. 
diminution occurs. These trends suggest that the incipiently produced 2B $@$ CB8 has larger fluorescence quantum yield than $\mathrm{B}^{+} @ \mathrm{CB} 8$, which predominates in the presence of substantial CB8 excess. Analysis of the fluorescence titration data with the consecutive 1:1 and 2:1 bindings model resulted in accurate fit (Figure 2B) with $\mathrm{K}_{1}=(9.5 \pm 1.4) \times 10^{6} \mathrm{M}^{-1}$ and $\mathrm{K}_{2}=(2.2 \pm 0.6) \times 10^{6}$ $\mathrm{M}^{-1}$ in accordance with the results of the spectrophotometric measurements (vide supra). Figure 4 presents the calculated mole fractions of the fluorescent species as a function of CB8 concentration. At $3.6 \mu \mathrm{M} \mathrm{B}^{+}$concentration, the mole fraction of $2 \mathrm{~B}^{+} @ \mathrm{CB} 8$ never exceeds 0.44 and $\mathrm{B}^{+} @ \mathrm{CB} 8$ dominates above $2.4 \mu \mathrm{M}$ CB8 concentration.

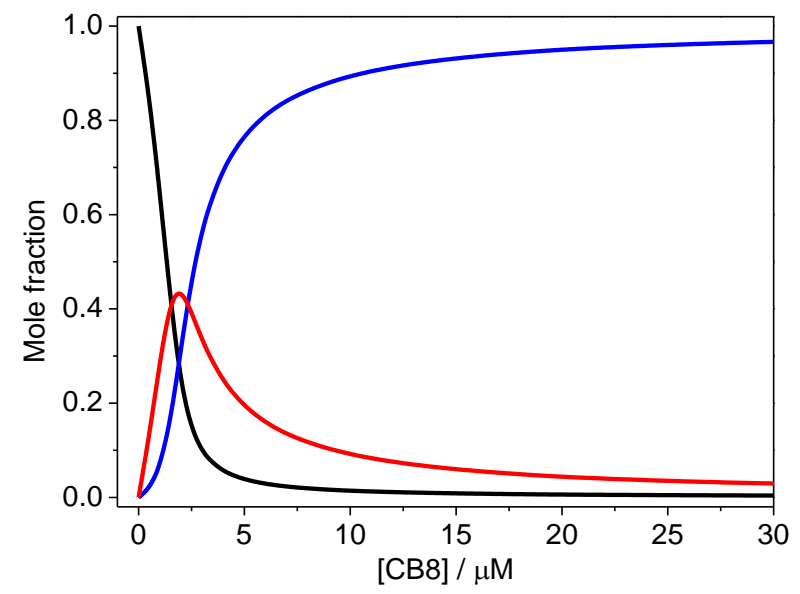

Figure 4. (A) Calculated mole fractions of $\mathrm{B}^{+}$(black line), 2B $\mathrm{B}^{+} @ \mathrm{CB} 8$ (red line), and $\mathrm{B}^{+} @ \mathrm{CB} 8$ (blue line) complexes at the equilibrium. $\left[\mathrm{B}^{+}\right]=3.6 \mu \mathrm{M}$

The fluorescence quantum yield of $\mathrm{B}^{+} @ \mathrm{CB} 8\left(\Phi_{\mathrm{F}}\left(\mathrm{B}^{+} @ \mathrm{CB} 8\right)\right)$ was determined using $\mathrm{B}^{+} @ \mathrm{CB} 7$ as reference, for which $\Phi_{\mathrm{F}}\left(\mathrm{B}^{+} @ \mathrm{CB} 7\right)=0.26$ was reported. ${ }^{50}$ The $\mathrm{B}^{+} @ \mathrm{CB} 8$ and $\mathrm{B}^{+} @ \mathrm{CB} 7$ solutions had the same absorbance at the excitation wavelength of $345 \mathrm{~nm}$. The $\mathrm{B}^{+}$and host concentrations were $4.6 \mu \mathrm{M}$ and $110 \mu \mathrm{M}$, respectively. At such a substantial excess of 
cavitand, practically all $\mathrm{B}^{+}$produced 1:1 complex. The integral (I) of the fluorescence band intensity of $\mathrm{B}^{+} @ \mathrm{CB} 8$ and $\mathrm{B}^{+} @ \mathrm{CB} 7$ were determined, and $\Phi_{\mathrm{F}}\left(\mathrm{B}^{+} @ \mathrm{CB} 8\right)=0.023 \pm 0.002$ fluorescence quantum yield was calculated using the following relationship:

$$
\Phi_{F}\left(\mathrm{~B}^{+} @ \mathrm{CB} 8\right)=\Phi_{F}\left(\mathrm{~B}^{+} @ \mathrm{CB} 7\right) \frac{I\left(\mathrm{~B}^{+} @ \mathrm{CB} 8\right)}{I\left(\mathrm{~B}^{+} @ \mathrm{CB} 7\right)} \frac{\left(1-10^{-A\left(\mathrm{~B}^{+} @ \mathrm{CB} 7\right)}\right)}{\left(1-10^{-A\left(\mathrm{~B}^{+} @ \mathrm{CB} 8\right)}\right)}
$$

The quantum yield of 2B+@ $\mathrm{CB} 8$ emission was measured using $\mathrm{B}^{+} @ \mathrm{CB} 8$ as reference. Two samples were prepared. Sample 1 contained $3.6 \mu \mathrm{M} \mathrm{B}^{+}$and $2.4 \mu \mathrm{M} \mathrm{CB} 8$, whereas the reference had $3.6 \mu \mathrm{M} \mathrm{B}^{+}$and $110 \mu \mathrm{M}$ CB8. These solutions showed an isosbestic point at 384 $\mathrm{nm}$, which was chosen as excitation wavelength for the fluorescence spectra. Because the molar absorption coefficients were equal in the isosbestic point, the absorbace of $2 \mathrm{~B}^{+} @ \mathrm{CB} 8$ $\left(\mathrm{A}\left(2 \mathrm{~B}^{+} @ \mathrm{CB} 8\right)\right)$ was calculated from the total absorbance of sample $1\left(\mathrm{~A}_{\mathrm{T}}\right)$ using the molar fraction of 2B+e $@ \mathrm{CB} 8\left(\mathrm{X}\left(2 \mathrm{~B}^{+} @ \mathrm{CB} 8\right)\right)$ presented in Figure 4:

$$
A\left(2 \mathrm{~B}^{+} @ \mathrm{CB} 8\right)=A_{T} X\left(2 \mathrm{~B}^{+} @ \mathrm{CB} 8\right)
$$

Analogously, the integrated intensity of $2 \mathrm{~B}^{+} @ \mathrm{CB} 8\left(\mathrm{I}\left(2 \mathrm{~B}^{+} @ \mathrm{CB} 8\right)\right)$ was obtained as follows:

$$
I\left(2 \mathrm{~B}^{+} @ \mathrm{CB} 8\right)=I_{T} X\left(2 \mathrm{~B}^{+} @ \mathrm{CB} 8\right)
$$

where $I_{T}$ stands for the total integrated intensity emitted from sample 1. The integrated intensities of sample 1 and the reference $\mathrm{B}^{+} @ \mathrm{CB} 8$ solution $\left(\mathrm{I}\left(\mathrm{B}^{+} @ \mathrm{CB} 8\right)\right)$ were determined under the same experimental conditions. The substitution of the derived quantities into the expression

$$
\Phi_{F}\left(2 \mathrm{~B}^{+} @ \mathrm{CB} 8\right)=\Phi_{F}\left(\mathrm{~B}^{+} @ \mathrm{CB} 8\right) \frac{I\left(2 \mathrm{~B}^{+} @ \mathrm{CB} 8\right)}{I\left(\mathrm{~B}^{+} @ \mathrm{CB} 8\right)} \frac{\left(1-10^{-A\left(\mathrm{~B}^{+} @ \mathrm{CB} 8\right)}\right)}{\left(1-10^{-A\left(2 \mathrm{~B}^{+} @ \mathrm{CB} 8\right)}\right)}
$$

provided $\Phi_{\mathrm{F}}\left(2 \mathrm{~B}^{+} @ \mathrm{CB} 8\right)=0.043 \pm 0.004$ for the fluorescence quantum yield of $2 \mathrm{~B}^{+} @ \mathrm{CB} 8$.

Time-resolved measurements also confirmed the sequential confinement of two guests in CB8. The feeble emission of $\mathrm{B}^{+}$with about $40 \mathrm{ps}$ fluorescence lifetime ${ }^{53}\left(\tau_{\mathrm{F}}\right)$ vanished upon addition of CB8, and a fluorescence component of $4.1 \mathrm{~ns}$ lifetime appeared due to $2 \mathrm{~B}^{+} @ \mathrm{CB} 8$ 
formation. Upon further increase of CB8 amount, another fluorescence component with $2.0 \mathrm{~ns}$ lifetime emerged with growing amplitude implying the transformation of $2 \mathrm{~B}^{+} @ \mathrm{CB} 8$ to B $@ \mathrm{CB} 8$.

The photophysical parameters of the inclusion complexes are summarized in Table 1. For the sake of comparison, the corresponding data of $\mathrm{B}^{+} @ \mathrm{CB} 7$ are also listed. The rate constant of the radiative deactivation from the singlet-excited state $\left(\mathrm{k}_{\mathrm{F}}=\Phi_{\mathrm{F}} / \tau_{\mathrm{F}}\right)$ barely differs for $2: 1$ and 1:1 CB8 complexes, but about twice larger value was found for $\mathrm{B}^{+} @ \mathrm{CB} 7$. The substantial change in the fluorescence lifetimes originates from the alteration of the rate constant of the nonradiative processes $\left(\mathrm{k}_{\mathrm{nr}}=\left(1-\Phi_{\mathrm{F}}\right) / \tau_{\mathrm{F}}\right)$.

Table 1. Photophysical parameters of $\mathrm{B}^{+}$in $\mathrm{CBn}$ cavities at $298 \mathrm{~K}$ in water

\begin{tabular}{|l|c|c|c|}
\hline & $2 \mathrm{~B}^{+} @ \mathrm{CB} 8$ & $\mathrm{~B}^{+} @ \mathrm{CB} 8$ & $\mathrm{~B}^{+} @ \mathrm{CB} 7$ \\
\hline$\lambda_{\mathrm{F}}(\mathrm{max}) / \mathrm{nm}$ & $532 \pm 1$ & $527 \pm 1$ & $500 \pm 1$ \\
\hline$\Phi_{\mathrm{F}}$ & $0.043 \pm 0.004$ & $0.023 \pm 0.002$ & $0.26 \pm 0.02^{a}$ \\
\hline$\tau_{\mathrm{F}} / \mathrm{ns}$ & $4.1 \pm 0.1$ & $2.0 \pm 0.1$ & $11.6 \pm 0.5^{a}$ \\
\hline $\mathrm{k}_{\mathrm{F}} / 10^{8} \mathrm{~s}^{-1}$ & $0.10 \pm 0.02$ & $0.12 \pm 0.02$ & $0.22 \pm 0.02$ \\
\hline $\mathrm{k}_{\mathrm{nr}} / 10^{8} \mathrm{~s}^{-1}$ & $2.3 \pm 0.3$ & $4.9 \pm 0.5$ & $0.64 \pm 0.05$ \\
\multicolumn{2}{|l}{} & & \\
\hline
\end{tabular}

\section{Determination of the binding constant of $1: 1$ complexation by competitive method}

The competitive binding of $\mathrm{CB} 7$ to $\mathrm{B}^{+}$and the large $\Phi_{\mathrm{F}}$ of the produced inclusion complex were exploited for the selective determination of the equilibrium constant of $\mathrm{B}^{+} @ \mathrm{CB} 8$ formation. The 66-fold excess of $\mathrm{CB} 8$ relative to $\mathrm{B}^{+}$ensured the negligible extent of 2:1 association in the initial sample. Figure 5 illustrates the alteration of the fluorescence spectra upon gradual addition of 
CB7. The concentration of $\mathrm{B}^{+}$and CB8 were kept constant. The intensity enhancement and the hypsochromic displacement of the band indicate the transformation of $\mathrm{B}^{+} @ \mathrm{CB} 8$ into the stronger emitting $\mathrm{B}^{+} @ \mathrm{CB} 7$. The inset to Figure 5 displays the change of the fluorescence intensity at $500 \mathrm{~nm}$ as a function of $\mathrm{CB} 7$ concentration together with the result of the nonlinear

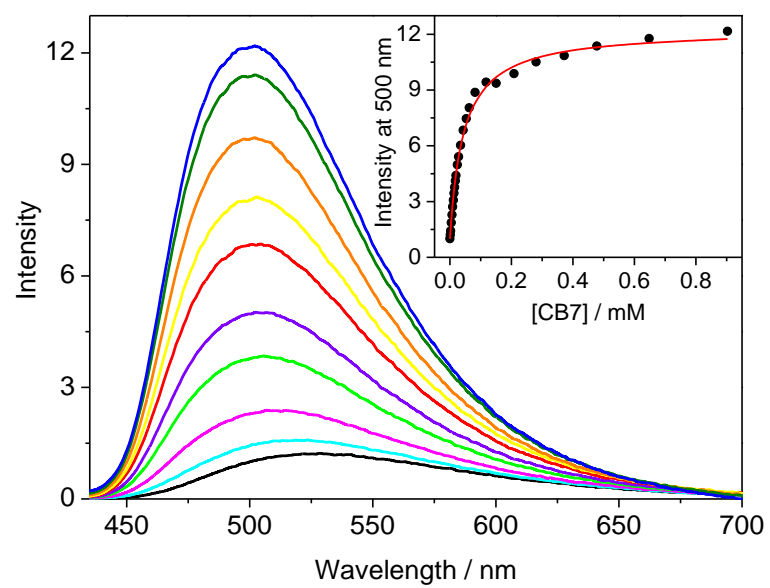

Figure 5. Effect of CB7 addition on the fluorescence spectra in $1.8 \mu \mathrm{M} \mathrm{B}{ }^{+}$and $120 \mu \mathrm{M} \mathrm{CB} 8$ mixture at 294 K. Excitation occurred at $340 \mathrm{~nm}$. Inset: Variation of the fluorescence intensity with CB7 concentration. The line represents the fitted function.

regression analysis. Competitive 1:1 inclusion of $\mathrm{B}^{+}$in $\mathrm{CB} 8$ and $\mathrm{CB} 7$ was assumed. The binding constant for the latter host, $\mathrm{K}\left(\mathrm{B}^{+} @ \mathrm{CB} 7\right)=2.97 \times 10^{7} \mathrm{M}^{-1}$ at $294 \mathrm{~K}$, was taken from our previous study. ${ }^{44}$ The best fit of the experimental data gave $\mathrm{K}_{1}=(1.0 \pm 0.2) \times 10^{7} \mathrm{M}^{-1}$ in good agreement with the directly measured value (vide supra).

\section{Thermodynamic parameters of $\mathrm{B}^{+}$confinement in $\mathrm{CB8}$}

To reveal the thermodynamics of host-guest association, fluorescence titrations were repeated at various temperatures. First, the temperature dependence of the equilibrium constant of $\mathrm{B}^{+} @ \mathrm{CB} 8$ formation $\left(\mathrm{K}_{1}\right)$ was determined by the method of competitive embedment in CB7 described in 
the previous chapter. The binding constant of the $\mathrm{B}^{+}$inclusion in $\mathrm{CB} 7$ was calculated at various temperatures by the equation

$$
K\left(B^{+} @ C B 7\right)=\exp \left(\frac{\Delta S}{R}\right) \exp \left(-\frac{\Delta H}{R T}\right)
$$

using the published enthalpy $(\Delta \mathrm{H})$ and entropy $(\Delta \mathrm{S})$ values. ${ }^{44} \mathrm{R}$ stands for the gas constant. Because $K\left(\mathrm{~B}^{+} @ \mathrm{CB} 7\right)$ is known, only two fitting parameters, $K_{1}$ and the ratio of the fluorescence efficiencies of $\mathrm{B}^{+} @ \mathrm{CB} 8$ and $\mathrm{B}^{+} @ \mathrm{CB} 7$ at the detection wavelength, are involved in the analysis of competitive titration data. The van't Hoff plot of the calculated $\mathrm{K}_{1}$ values (blue squares) is presented in Figure 6.

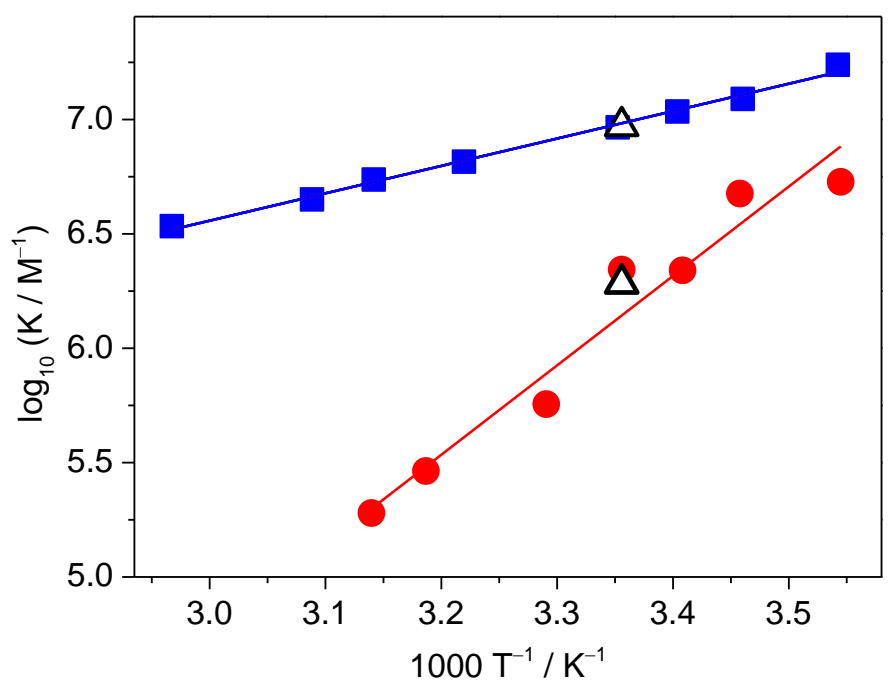

Figure 6. Logarithm of the binding constants for $\mathrm{B}^{+} @ \mathrm{CB} 8$ (blue squares) and $2 \mathrm{~B}^{+} @ \mathrm{CB} 8$ (red circles) determined by fluorescence method. The empty triangles represent the results of isothermal calorimetric titrations.

The equilibrium constant of $2 \mathrm{~B}^{+} @ \mathrm{CB} 8$ formation $\left(\mathrm{K}_{2}\right)$ was derived from the titration of $\mathrm{B}^{+}$with $\mathrm{CB} 8$ at various temperatures. The $\mathrm{K}_{1}$ values, determined as described above, were fixed in the analysis of the results. Figure 6 shows that $K_{2}$ is more sensitive to temperature than $K_{1}$. Consequently, the difference between the stability of 1:1 and 2:1 complexes significantly grows 
at higher temperature. The nonlinear least-squares fit of the temperature dependence of $\mathrm{K}_{1}$ and $\mathrm{K}_{2}$ with a relationship analogous to eqn. 5 provided the thermodynamic parameters summarized in Table 2.

Table 2. Thermodynamic parameters and binding constants for $\mathrm{B}^{+}$inclusion in $\mathrm{CBn}$ at $298 \mathrm{~K}$

\begin{tabular}{|l|c|c|c|}
\hline & \multicolumn{2}{|c|}{ CB8 host } & CB7 host $^{a}$ \\
\hline & $\begin{array}{c}\text { From fluorescence } \\
\text { titrations }\end{array}$ & $\begin{array}{c}\text { From calorimetric } \\
\text { measurements }\end{array}$ & $\begin{array}{c}\text { From calorimetric } \\
\text { measurements }\end{array}$ \\
\hline $\mathrm{K}_{1} / \mathrm{M}^{-1}$ & $(9.5 \pm 1.4) \times 10^{6}$ & $(9.4 \pm 1.2) \times 10^{6}$ & $(2.4 \pm 0.3) \times 10^{7}$ \\
\hline $\mathrm{K}_{2} / \mathrm{M}^{-1}$ & $(2.2 \pm 0.6) \times 10^{6}$ & $(1.9 \pm 0.3) \times 10^{6}$ & $b$ \\
\hline$\Delta \mathrm{G}_{1} / \mathrm{kJ} \mathrm{mol}^{-1}$ & $-40 \pm 0.5$ & $-40 \pm 0.5$ & $-42 \pm 0.4$ \\
\hline$\Delta \mathrm{H}_{1} / \mathrm{kJ} \mathrm{mol}^{-1}$ & $-23 \pm 3$ & $-25 \pm 2$ & $-38 \pm 2$ \\
\hline $\mathrm{T}_{\Delta} \mathrm{S}_{1} / \mathrm{kJ} \mathrm{mol}^{-1}$ & $17 \pm 3$ & $15 \pm 2$ & $13 \pm 4$ \\
\hline$\Delta \mathrm{S}_{1} / \mathrm{J} \mathrm{mol}^{-1} \mathrm{~K}^{-1}$ & $57 \pm 9$ & $50 \pm 3$ & $b$ \\
\hline$\Delta \mathrm{G}_{2} / \mathrm{kJ} \mathrm{mol}^{-1}$ & $-36 \pm 0.8$ & $-36 \pm 0.6$ & $b$ \\
\hline$\Delta \mathrm{H}_{2} / \mathrm{kJ} \mathrm{mol}^{-1}$ & $-75 \pm 10$ & $-69 \pm 4$ & $b$ \\
\hline $\mathrm{T}_{\Delta} \mathrm{S}_{2} / \mathrm{kJ} \mathrm{mol}^{-1}$ & $-39 \pm 6$ & $-33 \pm 3$ & $b \pm 9$ \\
\hline$\Delta \mathrm{S}_{2} / \mathrm{J} \mathrm{mol}^{-1} \mathrm{~K}^{-1}$ & $-130 \pm 20$ & $-110 \pm 9$ & $b$ \\
\hline
\end{tabular}

\footnotetext{
${ }^{a}$ Reference ${ }^{44},{ }^{b}$ No 2:1 complex formation
}

It is worth noting that $\mathrm{K}_{2}$ is among the highest equilibrium constants currently known for CB8 ternary complexes. (see Supporting Information in reference ${ }^{54}$ ) Only two ternary complexes are slightly more stable than $2 \mathrm{~B}^{+} @ \mathrm{CB} 8 . \mathrm{K}_{2}=2.7 \times 10^{6} \mathrm{M}^{-1}$ was found when 2-hydroxynaphthalene 
or 2,6-dihydroxynaphthalene was co-included with 1,2-bis(N-methyl-4-pyridyl)ethylene in CB8. $^{54}$

\section{Isothermal calorimetric studies}

To verify the enthalpy and entropy values obtained by fluorescence titrations, isothermal calorimetric measurements were performed. The latter method provides the most reliable information on the thermodynamics of inclusion complex formation due to the direct detection of the evolved reaction heat. However, the nonlinear least-squares analysis of the measured data
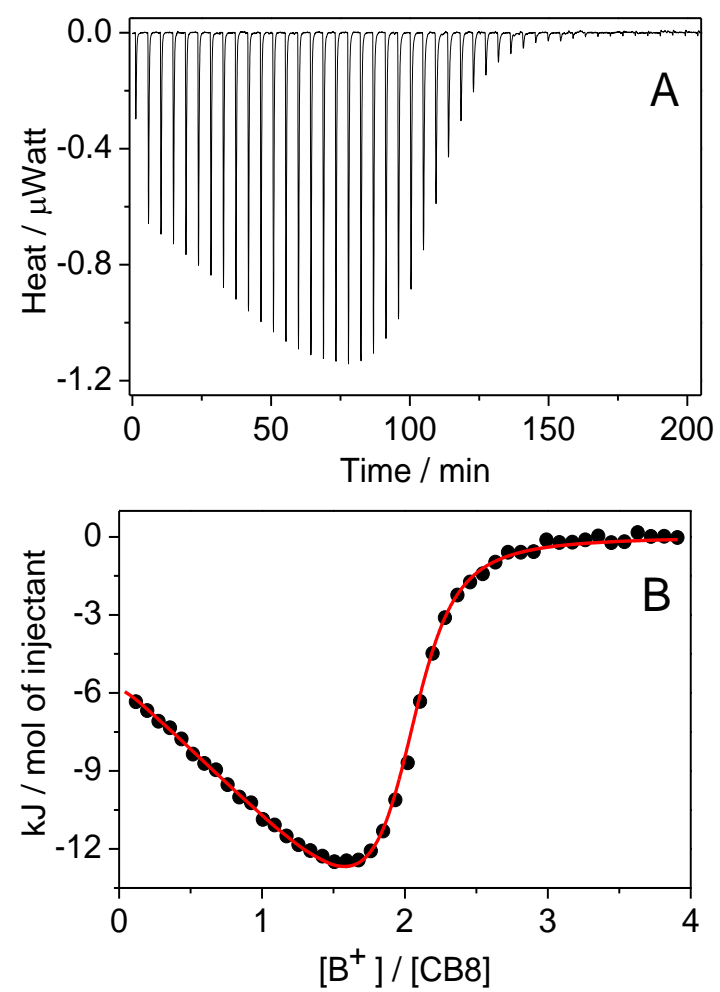

Figure 7. (A) Results of an isothermal calorimetric titration. (B) The integrated heat released per addition divided by the concentration of the injectant $(\bullet)$ was plotted as a function of the $\mathrm{B}^{+}$:CB8 molar ratio for the titration of $21 \mu \mathrm{M} \mathrm{CB} 8$ with $390 \mu \mathrm{M} \mathrm{B}^{+}$solution at $298 \mathrm{~K}$. The line shows the best fit with a stepwise binding to two sites model. 
is difficult in the case of stepwise binding equilibria ${ }^{30,55}$ because of the too many fitting parameters. We used the results of fluorescence titrations as starting values for the iterations. Successive amounts of $390 \mu \mathrm{M} \mathrm{B}^{+}$were added to $21 \mu \mathrm{M} \mathrm{CB} 8$ solution. After the initial growth, the released heat per injections decreased reaching an inflexion point at around $2: 1 \mathrm{~B}^{+}: \mathrm{CB} 8$ molar ratio. (Figure 7) This indicates two binding steps, and the substantially larger exothermicity of the second process. When the alkaloid solution was injected into water, negligible dilution heat was observed. Nonlinear least-squares fit of the titration data with a sequential binding to two sites model provided the binding constants $\left(\mathrm{K}_{1}=9.4 \times 10^{6} \mathrm{M}^{-1}\right.$ and $\mathrm{K}_{2}=$ $\left.1.9 \times 10^{6} \mathrm{M}^{-1}\right)$ as well as the enthalpy changes $\left(\Delta \mathrm{H}_{1}=-25.0 \mathrm{~kJ} \mathrm{~mol}^{-1}\right.$ and $\left.\Delta \mathrm{H}_{2}=-68.6 \mathrm{~kJ} \mathrm{~mol}^{-1}\right)$ for the two consecutive encapsulation equilibria. From these quantities, the standard free enthalpy $\left(\Delta \mathrm{G}_{\mathrm{n}}\right)$ and entropy changes $\left(\Delta \mathrm{S}_{\mathrm{n}}\right)$ were calculated on the basis of the relationship:

$$
\Delta G_{n}=-\mathrm{RT} \ln K_{n}=\Delta H_{n}-\mathrm{T} \Delta S_{n}
$$

where $\mathrm{R}$ denotes the gas constant, and $\mathrm{T}$ stands for the temperature. The data in Table 2 demonstrate that the parameters derived from calorimetric and fluorescence titrations agree within the limits of experimental errors.

\section{Kinetics of inclusion in CB8}

The negligible emission of $\mathrm{B}^{+}$in water and the substantial fluorescence intensity enhancement upon complexation permitted us to follow the association with CB8 in real time. To slow down the rapid bimolecular encapsulation, dilute reactant solutions were employed, and the experiments were carried out at $283 \mathrm{~K}$. Figure 8 presents the fluorescence intensity change at $535 \mathrm{~nm}$ after rapid mixing of $\mathrm{B}^{+}$and CB8 solutions. The initial alkaloid concentration was kept constant $(0.6 \mu \mathrm{M})$, and the amount of the host was increased. After a steep initial rise owing to 


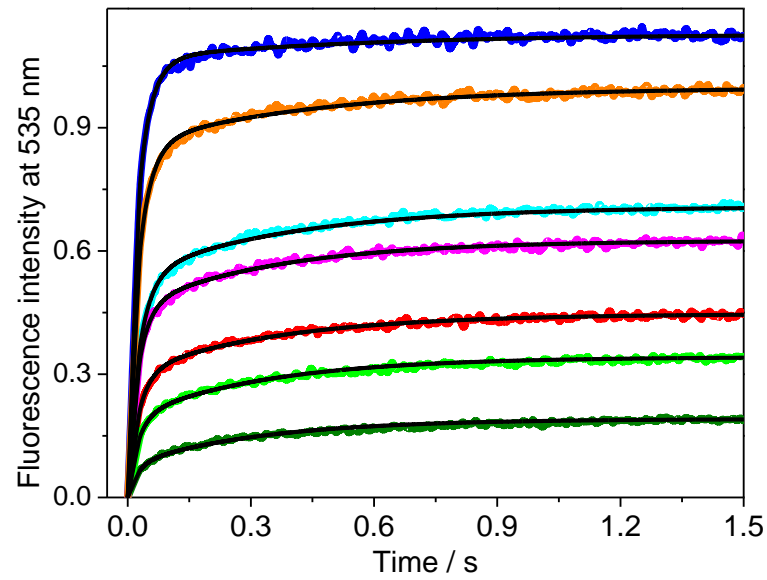

Figure 8. Stopped-flow signals detected at $535 \mathrm{~nm}$ for initial concentrations of $0.6 \mu \mathrm{M} \mathrm{B}^{+}$and (up from down) $0.046,0.070,0.093,0.12,0.15,0.23$, and $0.31 \mu \mathrm{M} \mathrm{CB} 8$. Excitation was at 345 nm. The black lines present the fitted curves.

1:1 binding, a slower fluorescence intensity enhancement appeared because of the encapsulation of the second $\mathrm{B}^{+}$in $\mathrm{CB} 8$. The equilibration time became shorter, whereas the intensity attained in the equilibrium grew with CB8 concentration. The following relationships described the binding kinetics:

$$
\begin{gathered}
\frac{d[B @ C B 8]}{d t}=k_{1}\left[B^{+}\right][C B 8]-k_{-1}\left[B^{+} @ C B 8\right]-k_{2}\left[B^{+}\right]\left[B^{+} @ C B 8\right]+k_{-2}\left[2 B^{+} @ C B 8\right] \\
\frac{d[2 B @ C B 8]}{d t}=k_{2}\left[B^{+}\right]\left[B^{+} @ C B 8\right]-k_{-2}\left[2 B^{+} @ C B 8\right]
\end{gathered}
$$

where $k_{1}, k_{-1}$ and $k_{2}, k_{-2}$ denoted the ingression and egression rate constants for 1:1 and 2:1 guest:host confinements, respectively. The numerical solution of this system of differential equations was fitted to the stopped-flow data keeping $k_{1} / k_{-1}=K_{1}=16.8 \times 10^{6} \mathrm{M}^{-1}$ and $k_{2} / k_{-2}=$ $K_{2}=8.25 \times 10^{6} \mathrm{M}^{-1}$ constant. These $K_{1}$ and $K_{2}$ values were derived from the thermodynamic parameters arising from isothermal calorimetric titrations using eqn. 5 and $\mathrm{T}=283 \mathrm{~K}$. The black 
lines in Figure 8 display the results of the nonlinear least-squares analysis, and the calculated rate constants are summarized in Table 3. These kinetic parameters also describe well the stopped-flow traces recorded at $0.35 \mu \mathrm{M} \mathrm{CB} 8$ and various $\mathrm{B}^{+}$initial concentrations (Figure 9).

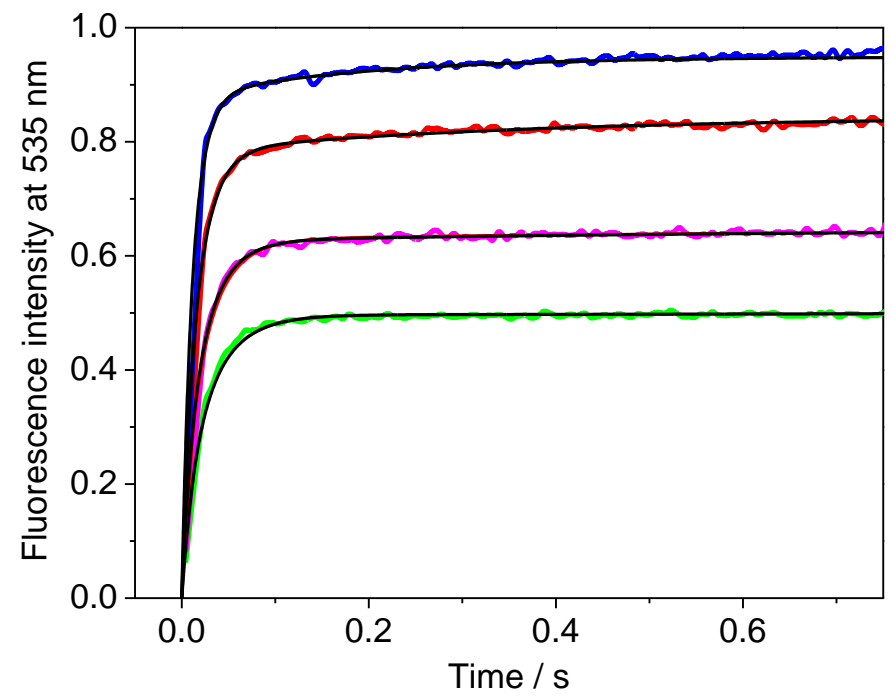

Figure 9. Stopped-flow signals measured at $0.35 \mu \mathrm{M}$ CB8 and (up from down) 0.50, 0.65, 0.98, and $1.5 \mu \mathrm{M} \mathrm{B}^{+}$initial concentrations at $283 \mathrm{~K}$. $\left(\lambda_{\text {excitation }}=345 \mathrm{~nm}\right)$ The black lines correspond to the function calculated with the rate constants listed in Table 3.

Table 3 Rate constants for the ingression $\left(k_{1}, k_{2}\right)$ and egression $\left(k_{-1}, k_{-2}\right)$ of $\mathrm{B}^{+}$at $283 \mathrm{~K}$ in neat water

\begin{tabular}{|l|c|c|}
\hline \multirow{2}{*}{ Rate constants } & \multicolumn{2}{|c|}{ Host compound } \\
\cline { 2 - 3 } & $\mathrm{CB} 8$ & $\mathrm{CB}^{a}$ \\
\hline $\mathrm{k}_{1} / \mathrm{M}^{-1} \mathrm{~s}^{-1}$ & $(64 \pm 9) \times 10^{6}$ & $(8.8 \pm 0.6) \times 10^{6}$ \\
\hline $\mathrm{k}_{-1} / \mathrm{s}^{-1}$ & $3.8 \pm 0.6$ & $0.16 \pm 0.02$ \\
\hline $\mathrm{k}_{2} / \mathrm{M}^{-1} \mathrm{~s}^{-1}$ & $(5.0 \pm 0.5) \times 10^{6}$ & $b$ \\
\hline $\mathrm{k}_{-2} / \mathrm{s}^{-1}$ & $0.6 \pm 0.1$ & $b$ \\
\hline
\end{tabular}

${ }^{a}$ reference ${ }^{44},{ }^{b}$ two $\mathrm{B}^{+}$cannot be encapsulated 


\section{DISCUSSION}

Comprehensive kinetic and thermodynamic study of inclusion complex formation with CB8 has not been reported due partly to the difficulty of the detection of the fast entry into the macrocycle. The insufficient difference in the rate constants and/or enthalpy of 1:1 and 2:1 encapsulations also renders the analysis of the experimental data problematic. Moreover, the similar spectral behaviors of the complexes usually hinder the selective detection.

We have demonstrated that these obstacles do not prevent the complete characterization of the inclusion in CB8 when $\mathrm{B}^{+}$is used as a guest. The fluorescence lifetime measurement is a highly sensitive method to distinguish the various $\mathrm{CBn}$ complexes of $\mathrm{B}^{+}$. (Table 1) This alkaloid is able to detect that water stays in the cavity of CB8 even after 1:1 complex formation because the rate of the internal conversion is significantly accelerated when the local polarity is enhanced. ${ }^{56}$ The long $\tau_{\mathrm{F}}$ for $\mathrm{B}^{+} @ \mathrm{CB} 7$ implies the removal of practically all water from $\mathrm{CB} 7$ upon embedment of $\mathrm{B}^{+}{ }^{44}$ On average, 13.1 water molecules reside in the more voluminous interior of $\mathrm{CB} 8 .{ }^{57}$ Only a fraction of these are expelled when a single $\mathrm{B}^{+}$is encapsulated. The interaction with the remnant water expedites the internal conversion from the singlet-excited state causing short (2 ns) $\tau_{\mathrm{F}}$ for $\mathrm{B}^{+} @ \mathrm{CB} 8$. The local polarity diminution, due to the replacement of the residual water upon the entry of the second $\mathrm{B}^{+}$into the host, results in twice larger $\tau_{\mathrm{F}}$ for 2B $\mathrm{B}^{+} \mathrm{CB} 8$, but the excited-state deactivation remains more rapid than in the case of $\mathrm{B}^{+} @ \mathrm{CB} 7$. This partly arises from the less deep embedment in CB8 when $2 \mathrm{~B}^{+}$cations are complexed (Figure 2). The enhanced water accessibility of $\mathrm{B}^{+}$caused thereby can lead to shorter $\tau_{\mathrm{F}}$ compared with that of $\mathrm{B}^{+} @ \mathrm{CB} 7$. The interaction between the $\pi$-electrons of the encapsulated isoquinoline rings may also accelerate the radiationless energy dissipation of the singlet-excited 2B $\mathrm{B}^{+} \mathrm{CB} 8$. 
About twice smaller equilibrium constant was found for the binding in CB8 than in the smaller CB7 macrocycle ${ }^{44}$ (Table 2$)$. Despite the slight $\left(\approx 2 \mathrm{~kJ} \mathrm{~mol}^{-1}\right)$ difference in the driving forces at $298 \mathrm{~K}$, the confinement is much less exothermic in CB8 than in CB7. Previous studies established that the removal of high-energy water molecules from CBn constitutes a major factor determining the binding affinity. ${ }^{54,57,58}$ The hydrogen bond network is less optimized and the electrostatic interactions among water molecules is weaker in the nonpolar, extremely nonpolarizable $\mathrm{CBn}$ core than in the bulk solvent. Therefore, the exclusion of the cavity-bound water molecules and their reassembling in the bulk can bring about a substantial enthalpy gain. ${ }^{57}$ The water network is less distorted in the larger CB8 than in CB7. As a consequence, the release of water from the former cavitand leads to less negative reaction enthalpy. The charge-dipole interactions also favorably contribute to the $\Delta \mathrm{H}_{1}$. This effect is larger for $\mathrm{B}^{+} @ \mathrm{CB} 7$ because of the better match between the sizes of the encapsulated dimethoxy-isoquinoline moiety and the CB7 cavity. The looser binding in CB8 allows weaker host-guest van der Waals interactions leading to smaller contribution to $\Delta \mathrm{H}_{1}$. Due to the hydrophobic character and the delocalized charge of $\mathrm{B}^{+}$, its desolvation energy probably barely affects $\Delta \mathrm{H}_{1}$.

Table 2 shows that $\mathrm{B}^{+}$encapsulation is always enthalpically driven. A significant entropy increase accompanies $\mathrm{B}^{+} @ \mathrm{CB} 8$ formation, whereas the confinement in CB7 causes only slight entropy gain. The displacement of water from the host cavity and from the solvate shell of $\mathrm{B}^{+}$is responsible for the entropy growth, which is partly compensated by the entropy diminution arising from the host-guest association and the integration of the released water molecules into the bulk solution. The larger $\Delta \mathrm{S}_{1}$ for $\mathrm{B}^{+} @ \mathrm{CB} 8$ compared to $\mathrm{B}^{+} @ \mathrm{CB} 7$ can be rationalized by the loose $\mathrm{B}^{+}$complexation in $\mathrm{CB} 8$, which ensures that few degrees of freedom become limited. 
Surprisingly, the association of $\mathrm{B}^{+}$with $\mathrm{B}^{+} @ \mathrm{CB} 8$ is much more exothermic than 1:1 complex formation (Table 2). This demonstrates that the release of high-energy water can overwhelm electrostatic repulsion between guest cations. Biedermann and Scherman have established that charge transfer interaction between guests of electron donor and acceptor characters is not the primary driving force of ternary complex formation with CB8. ${ }^{18}$ They developed a comprehensive model, which emphasized the pivotal role of the exclusion of highenergy water from CBn cavity in the stabilization of inclusion complexes. ${ }^{54,57}$ The concept, which explains the trends in the thermodynamic parameters of many CBn complexes, ${ }^{54,57}$ is also valid for the homoternary 2B $\mathrm{B}^{+} \mathrm{CB} 8$ associate. The number of cavity water molecules diminishes, but the energetic frustration of the residual water considerably increases upon embedment of a $\mathrm{B}^{+}$molecule in CB8 because energetically less optimized network can evolve in the remained small space. The much larger energy of the water in $\mathrm{B}^{+} @ \mathrm{CB} 8$ than in $\mathrm{CB} 8$ leads to larger enthalpy gain when the second $\mathrm{B}^{+}$expels water from the macrocycle into the bulk. Significantly smaller difference was observed between the enthalpy of $1: 1\left(\Delta \mathrm{H}_{1}=-44.0 \mathrm{~kJ}\right.$ $\left.\mathrm{mol}^{-1}\right)$ and 2:1 complexation $\left(\Delta \mathrm{H}_{2}=-51.5 \mathrm{~kJ} \mathrm{~mol}^{-1}\right)$ when the $\mathrm{N}$-terminal indole moieties of Trp-Gly-Gly tripeptide were embedded in CB8. ${ }^{30}$ In the case of other homoternary complexes, the thermodynamic parameters of the sequential binding steps could not be resolved. ${ }^{59,60}$

$\mathrm{B}^{+}$confinement in $\mathrm{B}^{+} @ \mathrm{CB} 8$ belongs to the most exothermic ternary complex formation processes of CB8 (see Supporting Information in reference ${ }^{54}$ ). More negative $\Delta \mathrm{H}_{2}$ was found only when secondary guests substituted with a long polyethylene glycol chain were confined to dicationic guest-CB8 complex. ${ }^{61}$ However, the entropic contribution of the inclusion is so unfavorable for these compounds that the driving force of ternary complexation becomes much

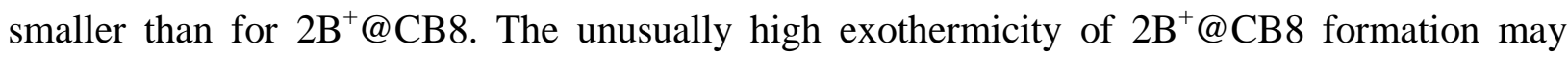


suggest that the release of water not only from the cavity but also from the portal region of CB8 favorably contributes to $\Delta \mathrm{H}_{2}$. As seen in Figure 2, a part of the spacious fused ring system of $\mathrm{B}^{+}$ protrudes from CB8 in one direction, whereas a methoxy group is located outside the other portal. Such an inclusion complex structure may increase the energy of the water molecules not only in the interior of the macrocycle but also in the vicinity of its entrances. The ingression of the second $\mathrm{B}^{+}$moves the first encapsulated guest slightly outwards from the macrocycle (Figure 2). Consequently, the water network alters at both carbonyl-fringed portals, which may contribute to the enthalpy gain of the second binding step.

The entropy diminution upon $2 \mathrm{~B}^{+} @ \mathrm{CB} 8$ formation $\left(\Delta \mathrm{S}_{2}\right.$ in Table 2$)$ can be rationalized by the largely reduced degrees of freedom of the components in the tightly packed ternary complex. When Trp-Gly-Gly tripeptide produced homoternary complex with CB8, Urbach and coworkers observed $\mathrm{T} \Delta \mathrm{S}_{2}=-26 \mathrm{~kJ} \mathrm{~mol}^{-1}$ for the entropy term. ${ }^{30}$ In that case, the relatively small indole substituents were encapsulated. Therefore, more space remained in the host cavity, and the degrees of freedom were limited to a lesser extent than in the ternary complex of the bulky $\mathrm{B}^{+}$. The transfer of high-energy water from the macrocycle to the bulk also plays a role in the entropy decrease. The lack of optimized interactions among cavity-water molecules provides more conformational freedom, which is lost when the released water joins to the solvent network in the bulk.

We have obtained about 7 times higher rate constant for $\mathrm{B}^{+}$ingression into $\mathrm{CB} 8$ than into CB7 (Table 3). Previous results proved that a constrictive binding takes place in the latter cavitand because its tight carbonyl-laced entrance constitutes a steric barrier. ${ }^{44}$ The $0.15 \mathrm{~nm}$ larger portal diameter $(\mathrm{d}=0.69 \mathrm{~nm})$ for $\mathrm{CB}^{51}$ is not wide enough to ensure $\mathrm{B}^{+}$inclusion without structural change. In the energy-minimized structure of $\mathrm{B}^{+}$, the largest distance between the 
hydrogen at the position 12 and the hydrogen of the 9-methoxy substituent was found to be 0.71 $\mathrm{nm}$. Taking into account the van der Waals radius of the atoms, it is evident that deformation of the reactants is needed to squeeze $\mathrm{B}^{+}$through the opening of $\mathrm{CB} 8$. Therefore, the entry rate constant is about 2 orders of magnitudes smaller than the rate constant of a diffusion controlled process $\left(6.5 \times 10^{9} \mathrm{M}^{-1} \mathrm{~s}^{-1}\right.$ at $\left.293 \mathrm{~K}\right) .{ }^{62}$ Not only the association but also the exit from CB8 is faster compared with the corresponding process of $\mathrm{CB} 7$ because of the weaker steric hindrance in the case of the former more spacious macrocycle. The about 24 times more rapid dissociation of $\mathrm{B}^{+} @ \mathrm{CB} 8$ compared with $\mathrm{B}^{+} @ \mathrm{CB} 7$ (Table 3 ) is probably due to the smaller activation energy caused by the easier passage through the larger entrance of CB8.

Astonishingly, the confinement of the second $\mathrm{B}^{+}$is also fairly rapid $\left(\mathrm{k}_{2}=5.0 \times 10^{6} \mathrm{M}^{-1} \mathrm{~s}^{-1}\right)$. The electrostatic repulsion by the initially encapsulated guest and the limited space in $\mathrm{B}^{+} @ \mathrm{CB} 8$ cause only 13 -fold rate constant diminution as compared with the rate constant of the ingression into the uncomplexed CB8. 2B ${ }^{+} @ \mathrm{CB} 8$ and $\mathrm{B}^{+} @ \mathrm{CB} 7$ formations occur with similar rate constants. The slow escape of $\mathrm{B}^{+}$from $2 \mathrm{~B}^{+} @ \mathrm{CB} 8\left(\mathrm{k}_{-2}=0.6 \mathrm{~s}^{-1}\right)$ is attributed to the large endothermicity of the process, whose activation enthalpy exceeds $-\Delta \mathrm{H}_{2}=69 \mathrm{~kJ} \mathrm{~mol}^{-1}$, the enthalpy of $\mathrm{B}^{+}$dissociation from the 2:1 complex (Table 2). Although $-\Delta \mathrm{H}_{2}$ matches the activation enthalpy of $\mathrm{B}^{+}$release ${ }^{44}$ from $\mathrm{B}^{+} @ \mathrm{CB} 7$, the egression from $\mathrm{B}^{+} @ \mathrm{CB} 7$ is almost 4 times slower than from $2 \mathrm{~B}^{+} @ \mathrm{CB} 8$. The difference in the exit rate constants indicates that the removal of $\mathrm{B}^{+}$has a larger activation entropy $\left(\Delta S^{\ddagger}\right)$ from $2 \mathrm{~B}^{+} @ \mathrm{CB} 8$ than from $\mathrm{B}^{+} @ \mathrm{CB} 7$. In the latter case, $\Delta S^{\star}=-19 \mathrm{Jmol}^{-1} \mathrm{~K}^{-1}$ was found. ${ }^{44}$

The rate constant of $2 \mathrm{~B}^{+} @ \mathrm{CB} 8$ formation $\left(\mathrm{k}_{2}=(5.0 \pm 0.5) \times 10^{6} \mathrm{M}^{-1} \mathrm{~s}^{-1}\right)$ is significantly lower than the corresponding value $\left(9.6 \times 10^{7} \mathrm{M}^{-1} \mathrm{~s}^{-1}\right)$ estimated on the basis of oscillatory rheological measurements for the association of the polymer-linked methyl viologen and 
naphthoxy moieties inside $\mathrm{CB} 8 .^{32}$ The slower ternary complex production of $\mathrm{B}^{+}$probably originates primarily from its larger size, and to some extent, the electrostatic repulsion between the two cationic guests may also decelerate the coinclusion.

\section{CONCLUSIONS}

The unique fluorescence properties of $\mathrm{B}^{+}$facilitated the systematic study of the thermodynamic and kinetic details of the reversible 1:1 and 2:1 inclusion in CB8 macrocycle, which had not been possible with any other guests. Both association steps of $\mathrm{B}^{+}$occurred quickly, but their rate constants were 2-3 orders of magnitude lower than for a diffusion-controlled process. These results and molecular modeling calculations suggest that constrictive binding takes place not only with CB7 but also with the larger CB8 host because $\mathrm{B}^{+}$cannot pass through the carbonyllined portal without conformation modifications. The increase of the number of the glycoluril units from 7 to 8 in the macrocycle brings about only 7 -fold rise in the rate constant of 1:1 inclusion, but many orders of magnitude slower encapsulations are typical for the 6-membered homologue. In contrast to the multistep confinements in $\mathrm{CB} 6,{ }^{36-38}$ no intermediates are detected when the ingression is rapid such as the entry into $\mathrm{CB} 7^{40,44}$ and $\mathrm{CB} 8$ hosts. The rate constants for dissociation diminish in the series of $\mathrm{B}^{+} @ \mathrm{CB} 8>2 \mathrm{~B}^{+} @ \mathrm{CB} 8>\mathrm{B}^{+} @ \mathrm{CB} 7$, but the driving force of complexation does not follow the same trend indicating the lack of correlation between the kinetic and thermodynamic stabilities. This exemplifies that the kinetic behavior cannot be predicted on the bases of the binding constants of host-guest complexes. The knowledge of the rate constants of the reversible confinement is essential in many applications of CBn complexes, for example in the rational design of molecular devices, self-sorting systems and catalytic reactions. Due to their substantial stability, $\mathrm{CB} 8$ complexes of $\mathrm{B}^{+}$may be utilized in controlled release, targeted delivery and alkaloid formulations. The high driving force of $2 \mathrm{~B}^{+} @ \mathrm{CB} 8$ 
formation implies that the release of high energy water from the host cavity can efficiently overwhelm the electrostatic repulsion between cationic guests. To the best of our knowledge, $\mathrm{B}^{+}$ is the first guest that is able to sensitively detect water remaining in the CB8 cavity after inclusion complex formation.

\section{ACKNOWLEDGEMENT}

The authors very much appreciate the support of this work by the Hungarian Scientific Research Fund (OTKA, Grant K104201). Z. M. thanks the support of the János Bolyai Research Scholarship of the Hungarian Academy of Sciences.

\section{References}

1 E. Masson, X. Ling, R. Joseph, L. Kyeremeh-Mensah and X. Lu, RSC Adv., 2012, 2, 1213-1247.

2 D. Das and O. A. Scherman, Isr. J. Chem., 2011, 51, 537-550.

3 A. E. Kaifer, W. Li and S. Yi, Isr. J. Chem., 2011, 51, 496-505.

4 J. Lagona, P. Mukhopadhyay, S. Chakrabarti and L. Isaacs, Angew. Chem. Int. Ed., 2005, 44, 4844-4870.

5 K. Kim, N. Selvapalam, Y. H. Ko, K. M. Park, D. Kim and J. Kim, Chem. Soc. Rev., $2007,36,267-279$.

6 I. Ghosh and W. M. Nau, Adv. Drug Deliv. Rev., 2012, 64, 764-783.

7 B. C. Pemberton, R. Raghunathan, S. Volla and J. Sivaguru, Chem. Eur. J., 2012, 18, 12178-12190.

8 S. Ghosh and L. Isaacs, J. Am. Chem. Soc., 2010, 132, 4445-4454. 
9 C. Klock, R. N. Dsouza and W. M. Nau, Org. Lett., 2009, 11, 2595-2598.

10 Z. Miskolczy, M. Megyesi, G. Tárkányi, R. Mizsei and L. Biczók, Org. Biomol. Chem., 2011, 9, 1061-1070.

11 Z. Miskolczy and L. Biczók, J. Phys. Chem. B, 2011, 115, 12577-12583.

12 R. N. Dsouza, U. Pischel and W. M. Nau, Chem. Rev., 2011, 111, 7941-7980.

13 M. Florea, S. Kudithipudi, A. Rei, M. J. González-Álvarez, A. Jeltsch and W. M. Nau, Chem. Eur. J., 2012, 18, 3521-3528.

14 D. M. Bailey, A. Hennig, V. D. Uzunova and W. M. Nau, Chem. Eur. J., 2008, 14, 60696077.

15 F. Biedermann, E. Elmalem, I. Ghosh, W. M. Nau and O. A. Scherman, Angew. Chem. Int. Ed., 2012, 51, 7739-7743.

16 U. Rauwald, F. Biedermann, S. p. Deroo, C. V. Robinson and O. A. Scherman, J. Phys. Chem. B, 2010, 114, 8606-8615.

17 H.-J. Kim, J. Heo, W. S. Jeon, E. Lee, J. Kim, S. Sakamoto, K. Yamaguchi and K. Kim, Angew. Chem. Int. Ed., 2001, 40, 1526-1529.

18 F. Biedermann and O. A. Scherman, J. Phys. Chem. B, 2012, 116, 2842-2849.

19 Y. Liu, R. Fang, X. Tan, Z. Wang and X. Zhang, Chem. Eur. J., 2012, 18, 15650-15654.

20 Y. Liu, H. Yang, Z. Wang and X. Zhang, Chem. Asian J., 2013, 8, 1626-1632.

21 K. Kim, Chem. Soc. Rev., 2002, 31, 96-107.

22 Y. H. Ko, K. Kim, J.-K. Kang, H. Chun, J. W. Lee, S. Sakamoto, K. Yamaguchi, J. C. Fettinger and K. Kim, J. Am. Chem. Soc., 2004, 126, 1932-1933.

23 Y. J. Jeon, P. K. Bharadwaj, S. Choi, J. W. Lee and K. Kim, Angew. Chem. Int. Ed., 2002, 41, 4474-4476.

24 Y. H. Ko, E. Kim, I. Hwang and K. Kim, Chem. Commun., 2007, 1305-1315. 
25 J. del Barrio, P. N. Horton, D. Lairez, G. O. Lloyd, C. Toprakcioglu and O. A. Scherman, J. Am. Chem. Soc., 2013, 135, 11760-11763.

26 V. Sindelar, M. A. Cejas, F. M. Raymo, W. Z. Chen, S. E. Parker and A. E. Kaifer, Chem. Eur. J., 2005, 11, 7054-7059.

27 I. Hwang, A. Y. Ziganshina, Y. H. Ko, G. Yun and K. Kim, Chem. Commun., 2009, 416418.

28 W. S. Jeon, E. Kim, Y. H. Ko, I. Hwang, J. W. Lee, S.-Y. Kim, H.-J. Kim and K. Kim, Angew. Chem. Int. Ed., 2005, 44, 87-91.

29 M. E. Bush, N. D. Bouley and A. R. Urbach, J. Am. Chem. Soc., 2005, 127, 14511-14517.

30 L. M. Heitmann, A. B. Taylor, P. J. Hart and A. R. Urbach, J. Am. Chem. Soc., 2006, 128, 12574-12581.

31 W. Lei, G. Jiang, Q. Zhou, B. Zhang and X. Wang, Phys. Chem. Chem. Phys., 2010, 12, $13255-13260$.

32 E. A. Appel, F. Biedermann, U. Rauwald, S. T. Jones, J. M. Zayed and O. A. Scherman, J. Am. Chem. Soc., 2010, 132, 14251-14260.

33 B. C. Pemberton, R. K. Singh, A. C. Johnson, S. Jockusch, J. P. Da Silva, A. Ugrinov, N. J. Turro, D. K. Srivastava and J. Sivaguru, Chem. Commun., 2011, 47, 6323-6325.

34 W. L. Mock and N. Y. Shih, J. Org. Chem., 1986, 51, 4440-4446.

35 W. L. Mock and N. Y. Shih, J. Am. Chem. Soc., 1989, 111, 2697-2699.

36 C. Marquez and W. M. Nau, Angew. Chem. Int. Ed., 2001, 40, 3155-3160.

37 C. Márquez, R. R. Hudgins and W. M. Nau, J. Am. Chem. Soc., 2004, 126, 5806-5816.

38 X. Ling, E. L. Samuel, D. L. Patchell and E. Masson, Org. Lett., 2010, 12, 2730-2733.

39 R. Hoffmann, W. Knoche, C. Fenn and H.-J. Buschmann, J. Chem. Soc., Faraday Trans., 1994, 90, 1507-1511. 
40 H. Tang, D. Fuentealba, Y. H. Ko, N. Selvapalam, K. Kim and C. Bohne, J. Am. Chem. Soc., 2011, 133, 20623-20633.

41 P. Mukhopadhyay, P. Y. Zavalij and L. Isaacs, J. Am. Chem. Soc., 2006, 128, 1409314102.

42 M. H. Tootoonchi, S. Yi and A. E. Kaifer, J. Am. Chem. Soc., 2013, 135, 10804-10809.

43 Z. Miskolczy, J. G. Harangozó, L. Biczók, V. Wintgens, C. Lorthioir and C. Amiel, Photochem. Photobiol. Sci., 2014, 13, 499-508.

44 Z. Miskolczy and L. Biczók, J. Phys. Chem. B, 2014, 118, 2499-2505.

45 C. Bohne, Chem. Soc. Rev., 2014, 43, 4037-4050.

46 T. C. S. Pace and C. Bohne, Adv. Phys. Org. Chem., 2008, 42, 167-222.

47 D. H. Macartney, Isr. J. Chem., 2011, 51, 600-615.

48 S. Walker, R. Oun, F. J. McInnes and N. J. Wheate, Isr. J. Chem., 2011, 51, 616-624.

49 M. Megyesi and L. Biczók, J. Phys. Chem. B, 2010, 114, 2814-2819.

50 M. Megyesi, L. Biczók and I. Jablonkai, J. Phys. Chem. C, 2008, 112, 3410-3416.

51 J. Kim, I.-S. Jung, S.-Y. Kim, E. Lee, J.-K. Kang, S. Sakamoto, K. Yamaguchi and K. Kim, J. Am. Chem. Soc., 2000, 122, 540-541.

52 J. J. Inbaraj, B. M. Kukielczak, P. Bilski, S. L. Sandvik and C. F. Chignell, Chem. Res. Toxicol., 2001, 14, 1529-1534.

53 M. Megyesi and L. Biczók, J. Phys. Chem. B, 2007, 111, 5635-5639.

54 F. Biedermann, M. Vendruscolo, O. A. Scherman, A. De Simone and W. M. Nau, J. Am. Chem. Soc., 2013, 135, 14879-14888.

55 G. P. Tochtrop, K. Richter, C. Tang, J. J. Toner, D. F. Covey and D. P. Cistola, Proc. Natl. Acad. Sci. USA, 2002, 99, 1847-1852. 
56 H. Görner, Z. Miskolczy, M. Megyesi and L. Biczók, Photochem. Photobiol., 2011, 87, 284-291.

57 F. Biedermann, V. D. Uzunova, O. A. Scherman, W. M. Nau and A. De Simone, J. Am. Chem. Soc., 2012, 134, 15318-15323.

58 W. M. Nau, M. Florea and K. I. Assaf, Isr. J. Chem., 2011, 51, 559-577.

59 S. Sonzini, S. T. J. Ryan and O. A. Scherman, Chem. Commun., 2013, 49, 8779-8781.

60 Y. Liu, K. Liu, Z. Wang and X. Zhang, Chem. Eur. J., 2011, 17, 9930-9935.

61 F. Biedermann, U. Rauwald, M. Cziferszky, K. A. Williams, L. D. Gann, B. Y. Guo, A. R. Urbach, C. W. Bielawski and O. A. Scherman, Chem. Eur. J., 2010, 16, 13716-13722.

62 M. Montalti, A. Credi, L. Prodi and M. T. Gandolfi, Handbook of Photochemistry; 3rd ed., CRC Press: Boca Raton, FL, 2006.

\section{Graphical abstract}

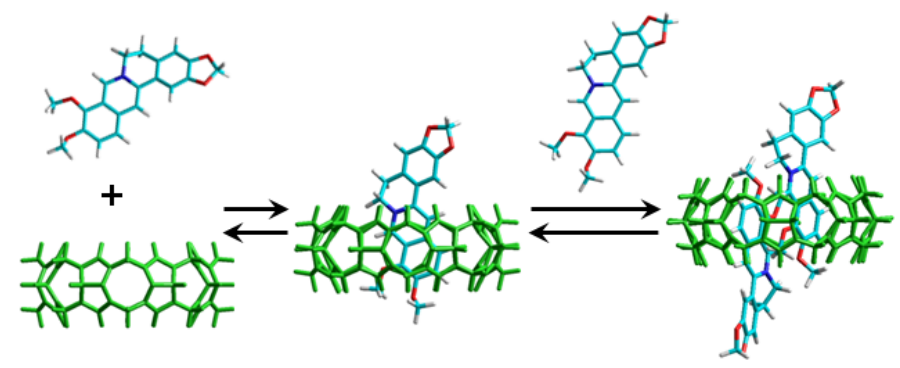


The formation and dissociation kinetics of 1:1 and 2:1 inclusion of berberine in cucurbit[8]uril cavity is revealed. 